Original Article

\title{
Intracranial hemorrhage in hemorrhagic disease of the newborn
}

\author{
Irawan Mangunatmadja, MD; Rina W Sundariningrum, MD; \\ Hardiono D Pusponegoro, MD; Endang Windiastuti, MD
}

\begin{abstract}
Background Hemorrhagic disease of the newborn (HDN) represents a special case of vitamin $\mathrm{K}$ deficiency because the four vitamin $\mathrm{K}$-coagulation factors (factors II, $\mathrm{VII}, \mathrm{IX}, \mathrm{X}$ ) are already at physiologically low levels in the newborn. It responds to vitamin $\mathrm{K}$ therapy.

Objective The aim of this study was to review the incidence, clinical manifestation, and outcome of HDN.

Methods This was a retrospective cross sectional study on 22 patients hospitalized for HDN in the Department of Child Health, Cipto Mangunkusumo Hospital from January 1997 until December 2001. Data were obtained from medical records.

Results The commonest age group (17 out of 22) was 1-3 monthold. Normal delivery was found in 19 patients and only 3 patients received prophylaxis vitamin $\mathrm{K}$. Almost all of them (20 out of 22) were exclusively breastfed. Seizure, pallor, decreased consciousness, and bulging of the anterior fontanel were significant clinical manifestations found in $21,21,13$, and 9 patients respectively. Based on brain USG and/or CT scan, intracranial hemorrhage was found in 19 patients. Six out of 22 patients died and 7 patients survived with handicap

Conclusion Intracranial hemorrhage due to vitamin $\mathrm{K}$ mostly occurred at the age of 1 to 3 month-old. The commonest clinical manifestations were seizure, pallor, decreased consciousness, and bulging of the anterior fontanel. Prevention by giving vitamin $\mathrm{K}$ routinely to all newborn babies is recommended [Paediatr Indones 2003;43:82-84].
\end{abstract}

Keywords: intracranial hemorrhage, hemorrhagic disease, vitamin $K$ deficiency, prophylaxis, acquired prothrombin complex deficiency.

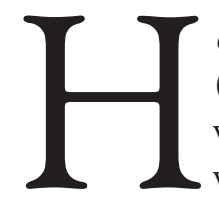

emorrhagic disease of the newborn (HDN) represents a special case of vitamin $\mathrm{K}$ deficiency because the four vitamin K-coagulation factors (factors II,VII,IX,X) are already at physiologically low levels in the newborn. ${ }^{1} \mathrm{HDN}$ is classified ${ }^{1-3}$ into: (1) early HDN which is confined to the first 24 hours of life; (2) classical HDN which occurs in the first 2 weeks of life; (3) late HDN which is observed predominantly in infants aged 2 weeks to 6 months, and (4) secondary vitamin $\mathrm{K}$ deficiency that occurs in the presence of underlying diseases such as liver disease, chronic diarrhea, and biliary atresia.

Late onset disease also known as acquired prothrombin complex deficiency (APCD) is associated with high incidence of central nervous system hemorrhage and mortality. ${ }^{1,2}$ Exclusive breast-feeding without vitamin $\mathrm{K}$ supplementation and failure to administer parenteral vitamin $\mathrm{K}$ at birth appear to be at least contributing factors in classic and late disease. ${ }^{1}$ The aim of this study was to review the incidence, clinical manifestations of HDN, and the outcome of the patients.

From the Department of Child Health, Medical School, University of Indonesia, Cipto Mangunkusumo Hospital, Jakarta.

Reprint requests to: Irawan Mangunatmadja, MD, Department of Child Health, Medical School, University of Indonesia, Jakarta, Indonesia. Tel. 62-21-3907740, Fax. 62-21-3907743. 


\section{Methods}

This was a retrospective cross sectional study done by reviewing the medical records of vitamin $\mathrm{K}$ deficiency bleeding in infants without history of head trauma who were hospitalized in the Department of Child Health, Cipto Mangunkusumo Hospital from January 1997 until December 2001. Diagnosis of HDN was based on bleeding symptoms with an acquired prolongation of the PT and PTT. ${ }^{1}$ The data of age, gender, clinical manifestations, peripheral blood examinations, PT, PTT, brain ultrasonography and /or CT scan, management, and outcome were collected.

\section{Results}

During the period of January 1997 until December 2001 there were 22 patients with age ranged from 1 month-9 months consisting of 12 males and 10 females. There were 20 patients of late HDN and 2 patients of secondary vitamin $\mathrm{K}$ deficiency. The commonest age group (17 out of 22) was 1-3 monthold. Most patients (19 out of 22) had gestational age of 37-42 weeks. Normal delivery was found in 19 patients and only 3 patients received vitamin $\mathrm{K}$ prophylaxis. Almost all of them (20 out of 22) were exclusively breastfed (Table 1 ).

Table 1. Characteristics of patients

\begin{tabular}{lr}
\hline Characteristics & Total \\
\hline Age (month) & 10 \\
$1-2$ & 7 \\
$2-3$ & 5 \\
$>3$ & \\
Gestational age (weeks) & 2 \\
$\quad<37$ & 19 \\
$37-42$ & 1 \\
$\quad>42$ & 19 \\
Delivery & 3 \\
$\quad$ Normal & \\
$\quad$ Cesarean section & 3 \\
Vitamin K prophylaxis & 16 \\
$\quad$ No & 3 \\
Questionable & \\
$\quad$ Yes & 20 \\
Feeding & 2 \\
$\quad$ Only breast milk & \\
$\quad$ With cow's milk & \\
\hline
\end{tabular}

Seizure, pallor, decreased consciousness, and bulging of the anterior fontanel were significant clinical manifestations found in 21, 21, 13 and 9 patients respectively. Most of patients had hemoglobin level $<10 \mathrm{~g} /$ $\mathrm{dl}$ (17 out of 22 patients). Based on brain USG and/or CT scan, intracranial hemorrhage $(\mathrm{ICH})$ was found in 16 patients. Six out of 22 patients died and 7 patients survived with handicap (Table 2).

Tabel 2. Clinical manifestations, laboratory \& brain IMAGING EXAMINATION, AND OUTCOME OF PATIENTS

\begin{tabular}{lr}
\hline & Total \\
\hline Symptoms & 21 \\
Seizure & 21 \\
Pallor & 13 \\
Consciousness: somnolence-sopor & 9 \\
Bulging of the anterior fontanel & 16 \\
Fever & 7 \\
Bleeding in other location & 6 \\
Cranial nerve palsy/hemiparesis & \\
$\quad$ & \\
Laboratory \& brain imaging examination & \\
Hemoglobin (g/dl) & 7 \\
$\quad<5$ & 10 \\
$\quad>10$ & 5 \\
Platelet (103/ul) & 1 \\
$\quad<100$ & 21 \\
$\quad$ Brain USG/CT scan ( $\mathrm{n}=19)$ & \\
$\quad$ Intracranial hemorrhage & 16 \\
$\quad$ & \\
Outcome & \\
$\quad$ Death & \\
$\quad$ Hand to follow up & 6 \\
Normal & 6 \\
\hline
\end{tabular}

\section{Discussion}

The commonest classification of HDN found in this study was late HDN (20 out of 22 patients), which was comparable with the commonest age group of 13 month-old (17 out of 22). Late HDN is observed mostly in infants with age of 1-3 months during which breast milk is the main source of food. ${ }^{1}$

Most patients (19 out of 22) had gestational age of 37-42 weeks. Normal delivery was found in 19 out of 22 patients, but only 3 patients received vitamin $\mathrm{K}$ prophylaxis. Almost all of them (20 out of 22) were exclusively breastfed. The vitamin $\mathrm{K}$ content in breast 
milk is very low $(2.5 \mathrm{mg} / \mathrm{L})$, only one-tenth from that in formula milk $(33 \mathrm{mg} / \mathrm{L}) .^{2}$ Newborns require $0.3 \mathrm{mg} /$ $\mathrm{kg} /$ day or $1 \mathrm{mg} /$ day of vitamin $\mathrm{K}$ and take about 500 $\mathrm{ml}$ of milk daily. Thus, the amount of vitamin $\mathrm{K}$ in breast milk may be insufficient to meet daily requirements, particularly from mothers with low milk secretion. $^{2}$

The presenting symptoms and signs of $\mathrm{ICH}$ were seizure, focal neurologic signs, or evidence of increased intracranial pressure (ICP). ${ }^{4}$ Seizure, pallor, decreased consciousness, and bulging of the anterior fontanel were significant clinical manifestations found in 21, 21, 13, and 9 patients respectively. These symptoms were considered of ICH. This condition was supported by brain USG or CT scan that showed ICH in 16 patients. The definitive diagnosis of $\mathrm{ICH}$ is achieved by non-contrast CT Scan. ${ }^{5}$

The management of all patients with anemia and prolongation of the PT and PTT were packed red cell transfusion, fresh frozen plasma, and vitamin $\mathrm{K}_{3} 1 \mathrm{mg}$ IM for 3 days. Vitamin $\mathrm{K}_{3}$ (menadione) is a synthetic compound with properties similar to those of vitamin $\mathrm{K}_{1}{ }^{6}$ The correction of prolonged PT can be achieved by the use of intravenous vitamin $K_{1}(5-25 \mathrm{mg})$, but the need for immediate normalization of this parameter often requires the use of fresh-frozen plasma $(10-20 \mathrm{~mL} / \mathrm{kg})$ or prothrombin complex concentrate. ${ }^{5}$

To decrease intracranial pressure due to intracranial hemorrhage, dexamethasone intravenous was given with or without furosemide intravenous or mannitol drip. Osmotic diuretics, particularly mannitol, are most helpful for the control of elevated ICP. It was given in a dose of $0.75-1 \mathrm{~g} / \mathrm{kg}$, followed by $0.25-0.50$ g/kg every 3-5 hour. This effect can be enhanced by the concomitant use of loop diuretics (furosemide). ${ }^{5}$ Corticosteroids are controversial in the management of increased ICP owing to ICH. ${ }^{5}$

In this study, the incidence of $\mathrm{ICH}$ was 16 out of 22. Mortality rate was high, 6 out of 22 patients and 7 patients survived with handicap. In late HDN, the incidence of intracranial bleeding is strikingly high (80\%) which results in high mortality rate (10-50\%) and neurological sequaele (30-50\%). ${ }^{2}$ In this study, only 3 out of 22 patients received vitamin K prophylaxis. The American Academy of Pediatrics recommended a routine administration of vitamin $\mathrm{K}$ prophylaxis ( $2 \mathrm{mg}$ orally or $1 \mathrm{mg}$ intramuscularly) to all newborn babies. ${ }^{2,7}$

In conclusion, $\mathrm{ICH}$ due to vitamin $\mathrm{K}$ deficiency most often occurs at the age of 1 to 3 months old with seizure, pallor, decreased consciousness, and bulging of the anterior fontanel as the commonest symptoms. We recommended prevention for this condition by giving of vitamin $\mathrm{K}$ routinely to all newborn babies.

\section{References}

1. Casella JF, Pelidis MA. Disorders of coagulation factors. In: McMillan JA, DeAngelis CD, Feigen RD, Warshaw JB, editors. Oski's pediatrics: principle and practice. $3^{\text {rd }}$ ed. Philadelphia: Lippincott Williams \&Wilkins; 1999. p. 1481-90.

2. Isarangkura PB. Vitamin K prophylaxis in newborn babies. J Paediatr Obstet Gynecol 1991;17:5-9.

3. Chuansumrit A, Isarangkura PB, Hathirat P. Vitamin $\mathrm{K}$ deficiency bleeding in Thailand: a 32-year history. Southeast Asian J Trop Med Pub Hlth 1998;29:649-54.

4. Komberg AJ, Prensky AL. Cerebrovascular disease. In: McMillan JA, DeAngelis CD, Feigen RD, Warshaw JB, editors. Oski's pediatrics: principle and practice. $3^{\text {rd }}$ ed. Philadelphia: Lippincott Williams \&Wilkins; 1999. p. 1928-36.

5. Steig PE, Kase CS. Intracranial hemorrhage: diagnosis and emergency management. Neurol Clin 1998;16:373-90.

6. Frank J, Aswal S. Neurologic disorders associated with gastrointestinal diseases, nutritional deficiencies, and fluid-electrolyte disorders. In: Swiman KE, Ashwal S, editors. Pediatric neurology: principles $\&$ practice. $3^{\text {rd }}$ ed. St Louis: Mosby; 1999. p. 1438-69.

7. Vitamin K Ad Hoc Task Force. American Academy of Pediatrics. Controversies concerning vitamin $\mathrm{K}$ and the newborn. Pediatrics 1993;91:1001-3. 